\title{
Catalytic metal-gate field effect transistors based on SiC for indoor air quality control
}

\author{
D. Puglisi ${ }^{1}$, J. Eriksson ${ }^{1}$, C. Bur ${ }^{1,2}$, A. Schuetze ${ }^{2}$, A. Lloyd Spetz ${ }^{1}$, and M. Andersson ${ }^{1}$ \\ ${ }^{1}$ Department of Physics, Chemistry and Biology, Applied Sensor Science, Linköping University, \\ 58183 Linköping, Sweden \\ ${ }^{2}$ Department of Physics and Mechatronics Engineering, Lab for Measurement Technology, Saarland University, \\ 66123 Saarbruecken, Germany \\ Correspondence to: D. Puglisi (donatella.puglisi@liu.se)
}

Received: 27 August 2014 - Revised: 23 October 2014 - Accepted: 29 November 2014 - Published: 6 January 2015

\begin{abstract}
High-temperature iridium-gated field effect transistors based on silicon carbide have been used for sensitive detection of specific volatile organic compounds (VOCs) in concentrations of health concern, for indoor air quality monitoring and control. Formaldehyde, naphthalene, and benzene were studied as hazardous VOCs at parts per billion (ppb) down to sub-ppb levels. The sensor performance and characteristics were investigated at a constant temperature of $330^{\circ} \mathrm{C}$ and at different levels of relative humidity up to $60 \%$, showing good stability and repeatability of the sensor response, and excellent detection limits in the sub-ppb range.
\end{abstract}

\section{Introduction}

Common living environments such as homes, schools, or workplaces, where the exposure to indoor air pollutants is continuous or prolonged, have become dangerous sites of health problems related to bad air quality. Symptoms include headache, dizziness, respiratory problems like asthma, skin irritation, hypersensitivity to odors and tastes, but also acute effects related to personality change or cancer, depending upon toxicological characteristics of the harmful substances, duration or frequency of exposure, people's age, and other related factors (Ashmore and Dimitroulopoulou, 2009; Salonen et al., 2009). Recently, the World Health Organization (WHO, 2010) released guidelines for a range of hazardous chemical substances belonging to the wide family of volatile organic compounds (VOCs) such as formaldehyde, naphthalene, and benzene, which are often found in indoor environments in concentrations of health concern.

For indoor air quality, all organic chemical compounds with the potential to evaporate under normal indoor atmospheric conditions (i.e., in the range of temperature and pressure usually found in buildings occupied by people) are defined as VOCs. A VOC is also defined as an organic compound having an initial boiling point less than or equal to $250^{\circ} \mathrm{C}$ at a pressure of $1 \mathrm{~atm}$. The higher the compound's volatility is (the lower the boiling point), the higher its tendency to be emitted from a product or surface into the air is (EPA, 2012).

The Total Exposure Assessment Methodology (TEAM) study by the United States Environmental Protection Agency (EPA)'s Office of Research and Development found already in 1985 levels of a dozen common organic pollutants to be 2 to 5 times higher indoors than outdoors, regardless of whether the homes were located in rural or industrial areas (Wallace, 1987). During and for several hours after certain activities, such as paint stripping, levels can reach 1000 times background outdoor levels. A proper reduction of VOCs is required for decreasing the atmospheric levels of air pollutants and reaching effective health protection measures.

Heating, ventilating, and air-conditioning (HVAC) systems are usually used to reduce exposure to VOCs, but they can result in considerable energy consumption, emissions, and cost. It has been estimated that HVAC systems account for $39 \%$ of the energy used in commercial buildings in the United States (Granham, 2009). In the last years, several initiatives and research projects have been supported by the European Union for the development of cost-effective sensors and sensor systems for monitoring and measurement of the 
indoor environmental quality. To reach this goal, different sensor technologies have been proposed, such as field effect gas-sensitive devices.

Field effect transistor devices based on silicon carbide (SiC-FETs) have been extensively studied in the last 15 years as high-performance, low-cost gas sensors for room- and high-temperature applications, such as emission monitoring, combustion control and exhaust after-treatment (Lloyd Spetz et al., 2013a, b; Andersson et al., 2004, 2013), and, more recently, indoor air quality applications (Puglisi et al., 2014; Bur et al., 2012). Due to the chemical inertness and wide bandgap of $\mathrm{SiC}$ ( $3.26 \mathrm{eV}$ for the $4 \mathrm{H}-\mathrm{SiC}$ polytype), gas sensors based on this semiconductor material have the potential to work efficiently in harsh environmental conditions, like corrosive atmospheres and high temperatures, with notable advantages in terms of stability during long-term operation and the possibility of direct online control. Such properties are suitable also for indoor air quality applications, where the environment is at room temperature, but the sensors must be operated at high temperature to allow sensitive and selective detection of certain gas species.

In this work, we study a sensor technology based on gassensitive SiC-FETs. Iridium (Ir) has been used as a sensing layer for the gate contact, whereby gas molecules may dissociate and react on the catalytic gate surface. This interaction charges the gate area and thereby changes the drain-tosource voltage, $V_{\mathrm{DS}}$, as the current through the transistor is kept constant. $V_{\mathrm{DS}}$ is utilized to measure the response to the target gas (Lloyd Spetz et al., 2013b). The study, evaluation, and choice of the catalytic material and its support (the gate dielectric) are important because the electrical performance of FET sensor devices as well as the chemical reactions responsible for the gas response depend on the type and nanostructure of the sensing layer processed onto the device (Lloyd Spetz et al., 2004), in conjunction with the nature and quality of the gate insulator (Schalwig et al., 2002; Eriksson et al., 2005).

The sensor response is highly temperature dependent. This is an advantage of gas-sensitive SiC-FET sensors for this kind of application because it is possible to obtain additional information about the presence of particular gases using the gas sensors under temperature-cycled operating conditions over a wide range of temperatures (Bur et al., 2012).

High-precision sensor performance tests have been carried out with specially developed instrumentation under controlled lab conditions. Tests included electrical characterization of the sensors, nanoscale structural and electrical characterization of the surface morphology and surface potential before and after gas exposure to VOCs to study potential gate degradation, and gas tests including variations of the target gas concentration and the humidity level.

We have already studied the temperature dependence on such Ir-gate SiC-FETs demonstrating that the best operating temperature is around $330^{\circ} \mathrm{C}$ (Puglisi et al., 2014), and we have quantitatively investigated Pt-gate SiC-FETs under dy- namic operation, demonstrating that temperature cycling is a powerful approach to increasing the selectivity of the gas sensors allowing discrimination of the three studied VOCs (Bur et al., 2014).

Here we have performed a systematic study on the influence of water on the Ir-gate SiC-FETs during highly sensitive VOC detection.

\section{Physical and chemical properties}

Formaldehyde is one of the best known VOCs, and a very common and hazardous indoor air pollutant. It is extensively used in the production of resins for use as adhesives and binders for wood products, paper or pulp. Formaldehyde is also contained in many construction materials, tobacco smoke, foods and cooking, paints, varnishes, floor finishes, and sanitary paper products. The eyes are most sensitive to formaldehyde exposure. The lowest level at which many people can smell formaldehyde is about $50 \mathrm{ppb}$. Acute toxicity to humans has been widely demonstrated, ranging from irritation of eyes and mucous membranes at concentrations of about $100 \mathrm{ppb}$ to more severe respiratory problems, nasal obstruction, pulmonary edema, choking, dyspnea, and chest tightness at higher concentrations of a few parts per million (ppm) after 1 week of exposure, as reported by the Air Toxicology and Epidemiology Branch of the Environmental Health Hazard Assessment Office of EPA (ATEB-EPA, 2008). A case study by Rumchev et al. (2002) on 6 month to 3 year old children demonstrated that children in homes with formaldehyde levels greater than $49 \mathrm{ppb}$ had a $39 \%$ higher risk of asthma than children exposed to less than $8 \mathrm{ppb}$. The International Agency for Research on Cancer (IARC) of the WHO concluded that formaldehyde is carcinogenic to humans. EPA considers formaldehyde a probable human carcinogen. WHO recommends an exposure limit of $81 \mathrm{ppb}$ for a short-term (30 $\mathrm{min})$ exposure time.

Naphthalene is a combustion product when organic materials are burned. Tobacco smoke, concrete and plasterboard, dyes, household fumigant, some air fresheners, cooking, and moth repellents may all be sources of naphthalene indoors (Agency for Toxic Substances and Disease Registry, 2010). Inhalation of naphthalene vapor has been associated with headaches, nausea, vomiting, confusion, and dizziness. Other health effects include damage or destruction of red blood cells, fatigue, lack of appetite, restlessness, pale skin, diarrhea, blood in the urine, jaundice, and haemolytic anaemia (in children). The characteristic naphthalene's strong odor of coal tar is detectable by humans at concentrations as low as $80 \mathrm{ppb}$. There is still inadequate evidence to evaluate the carcinogenicity of naphthalene to humans, but there is sufficient evidence in animals to conclude that naphthalene is carcinogenic (Gervais et al., 2010). IARC and EPA have classified naphthalene as a possible human car- 

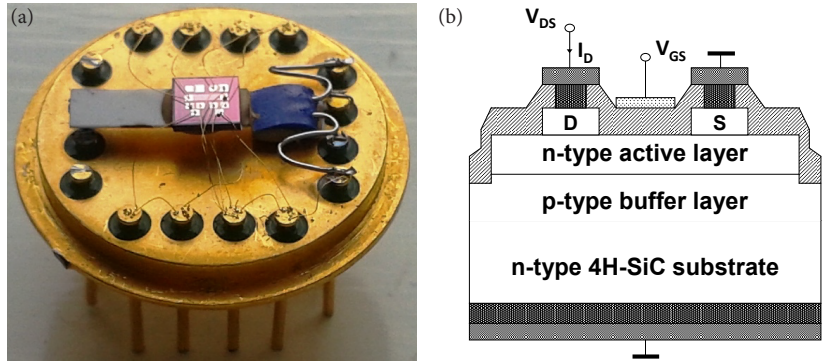

Figure 1. (a) Sensor chip mounted on a 16-pin TO8 header and glued on a ceramic heater together with a Pt100 temperature sensor. (b) Cross-sectional view of the $\mathrm{SiC}$ based field effect transistor used in this work.

cinogen. The WHO recommends an exposure limit of $1.9 \mathrm{ppb}$ (annual average).

Benzene exists mostly in the vapor phase, and it is reactive with photochemically produced hydroxyl radicals with a calculated half-life of 13.4 days. In atmospheres polluted with $\mathrm{NO}_{\mathrm{x}}$ or $\mathrm{SO}_{2}$, its half-life can be as short as $4-6 \mathrm{~h}$ (ATEB-EPA, 2008). Tobacco smoke, dyes, detergents, glues, paints, and furniture wax may all be sources of benzene indoors. Inhalation exposure to benzene may lead to eye, nose, and throat irritation, central nervous system depression in humans, bone marrow failure, leukaemia, and cancer. The IARC and EPA have classified benzene as a known human carcinogen for all routes of exposure. According to WHO, there is no safe level of exposure to benzene. However, the French Decree no. 2011-1727 (2011) has established an exposure limit of $0.6 \mathrm{ppb}$ by 2016 for public buildings.

The main characteristics of the three VOCs studied in this work are reported in Table 1.

\section{Experimental}

\subsection{Device fabrication}

Metal insulator semiconductor field effect transistors (MISFETs) with catalytic metal-gate contacts were fabricated on top of 4 inch n-type $4 \mathrm{H}-\mathrm{SiC}$ wafers by SenSiC AB, Sweden ${ }^{1}$. A p-type buffer layer of $1 \mu \mathrm{m}$ thickness and $1 \times 10^{17} \mathrm{~cm}^{-3}$ doping concentration, an n-type active layer of $400 \mathrm{~nm}$ thickness and $3 \times 10^{16} \mathrm{~cm}^{-3}$ doping concentration and an n-type contact layer of $300 \mathrm{~nm}$ thickness and about $1 \times 10^{20} \mathrm{~cm}^{-3}$ doping concentration were epitaxially grown on top of the $4 \mathrm{H}-\mathrm{SiC}$ substrate. The highly doped drain and source regions were subsequently created by etch-back. The ohmic contacts (bonding pads) to source, drain, and the substrate were formed by rapid thermal annealing of $50 \mathrm{~nm}$ nickel $(\mathrm{Ni})$ at $950^{\circ} \mathrm{C}$ in an argon (Ar) atmosphere and sputter deposition of $10 \mathrm{~nm}$ titanium (Ti) plus $400 \mathrm{~nm}$ platinum $(\mathrm{Pt})$ on top of

\footnotetext{
${ }^{1}$ SenSiC AB: Clean Air Sensors, Isafjordsgatan 39 B, 16440 Kista/Stockholm, Sweden.
}

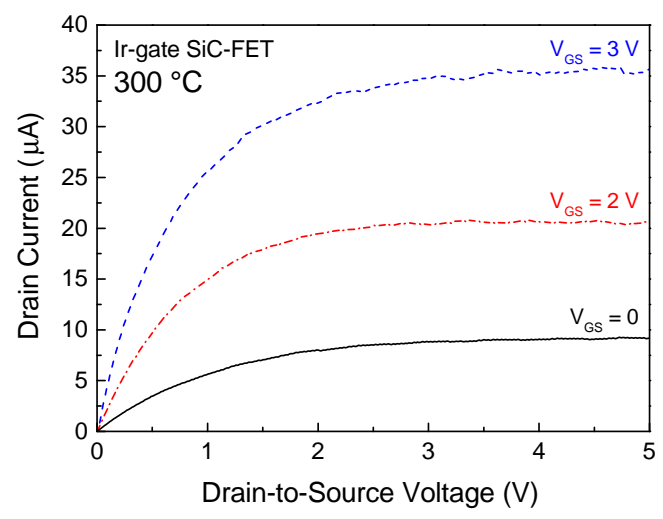

Figure 2. Current-voltage characteristics of an Ir-gate SiC-FET at $300^{\circ} \mathrm{C}$ with zero, $2 \mathrm{~V}$, and $3 \mathrm{~V}$ applied gate bias, $V_{\mathrm{GS}}$, after exposure to VOCs.

the Ni layer. The Pt layer works as an oxygen diffusion barrier as well as bonding pad material. A porous iridium (Ir) gate contact was deposited by dc magnetron sputtering at an Ar pressure of $50 \mathrm{mTorr}$ to a total thickness of $30 \mathrm{~nm}$. The gate width is $300 \mu \mathrm{m}$ and the corresponding gate length is $10 \mu \mathrm{m}$, with a separation between the gate and the sourceto-drain contacts of $5 \mu \mathrm{m}$ (Andersson et al., 2013). A crosssectional view of the $\mathrm{SiC}$ based MISFET used in this work is shown in Fig. 1a. The sensor chip, which is $2 \mathrm{~mm} \times 2 \mathrm{~mm}$ and contains four SiC-FET devices, is attached to a heater substrate (Heraeus PT 6.8/1020) together with a Pt100 temperature sensor, using high temperature, and non-conducting ceramic die (Fig. 1b). The electrical contacts of the heater substrate and the Pt100 temperature sensor were established by spot welding to two pairs of pins of the gold-plated 16-pin TO8 header. Electrical connections to the SiC-FET devices were made using gold wire bonding.

\subsection{Electrical characterization}

Before testing as highly sensitive gas sensors, several SiCFETs were characterized by means of current-voltage ( $I-$ $V$ ) measurements at 100,200 , and $300^{\circ} \mathrm{C}$. A source meter Keithley 2601 was used to operate the devices sweeping the voltage over the drain-to-source contacts, $V_{\mathrm{DS}}$, from 0 to $5 \mathrm{~V}$ at a rate of $0.1 \mathrm{~V} \mathrm{~s}^{-1}$, and measuring the drain current, $I_{\mathrm{D}}$. Separate gate voltages, $V_{\mathrm{GS}}$, up to $5 \mathrm{~V}$ were applied using a stabilized voltage source. $I-V$ measurements were carried out in synthetic air $\left(81 \% \mathrm{~N}_{2} / 19 \% \mathrm{O}_{2}\right.$, at a flow rate of $100 \mathrm{~mL} \mathrm{~min}^{-1}$ ) for all temperatures and $\mathrm{V}_{G S}$ values. The electrical characterization was repeated after exposure to VOCs. Figure 2 shows the drain currents measured at $300^{\circ} \mathrm{C}$ on an Ir-gate SiC-FET biasing the gate contact at zero, 2, and $3 \mathrm{~V}$ after exposure to VOCs.

The saturation currents, $I_{\text {Dsat }}$, measured on six Ir-gate $\mathrm{SiC}$ FETs at $300^{\circ} \mathrm{C}$ and $2 \mathrm{~V}$ applied $V_{\mathrm{GS}}$ before and after exposure to VOCs are shown in Fig. 3. In all cases, a variation of 
Table 1. Main characteristics of formaldehyde, naphthalene, and benzene.

\begin{tabular}{|c|c|c|c|}
\hline Property & Formaldehyde & Naphthalene & Benzene \\
\hline Molecular formula & $\mathrm{CH}_{2} \mathrm{O}$ & $\mathrm{C}_{10} \mathrm{H}_{8}$ & $\mathrm{C}_{6} \mathrm{H}_{6}$ \\
\hline Molecular weight & $30.03 \mathrm{~g} \mathrm{~mol}^{-1}$ & $128.19 \mathrm{~g} \mathrm{~mol}^{-1}$ & $78.11 \mathrm{~g} \mathrm{~mol}^{-1}$ \\
\hline Boiling point @ $1 \mathrm{~atm}$ & $-19.5^{\circ} \mathrm{C}$ & $218^{\circ} \mathrm{C}$ & $80.1^{\circ} \mathrm{C}$ \\
\hline $\begin{array}{l}\text { Appearance } \\
\text { @ room temperature }\end{array}$ & Colorless gas & White solid crystal or powder & Colorless liquid \\
\hline Odor@ room temperature & Pungent, irritating & Strong odor of coal tar & Aromatic (sweet), gasoline-like \\
\hline Odor threshold* & $0.83 \mathrm{ppm}$ & $0.084 \mathrm{ppm}$ & $1.5 \mathrm{ppm}$ \\
\hline $\begin{array}{l}\text { Conversion factor } \\
\left.\text { (in air, at } 25^{\circ} \mathrm{C}\right)^{*}\end{array}$ & $1 \mathrm{ppm}=1.23 \mathrm{mg} \mathrm{m}^{-3}$ & $1 \mathrm{ppm}=5.24 \mathrm{mg} \mathrm{m}^{-3}$ & $1 \mathrm{ppm}=3.19 \mathrm{mg} \mathrm{m}^{-3}$ \\
\hline Main hazard* & Probable human carcinogen & Possible human carcinogen & Known human carcinogen \\
\hline Health effects & $\begin{array}{l}\text { Eye and nasal irritation, } \\
\text { asthma, damage to pulmonary } \\
\text { function, reproductive prob- } \\
\text { lems in women, allergies, } \\
\text { dermatitis, leukemia, cancer }\end{array}$ & $\begin{array}{l}\text { Nausea, vomiting, dizziness, fa- } \\
\text { tigue, confusion, lack of ap- } \\
\text { petite, pale skin, diarrhea, blood } \\
\text { in the urine, damage or destruc- } \\
\text { tion of red blood cells }\end{array}$ & $\begin{array}{l}\text { Eye, nose, and throat irritation, } \\
\text { depression, bone marrow fail- } \\
\text { ure, leukemia, cancer (targets: } \\
\text { liver, kidney, lung, heart, and } \\
\text { brain) }\end{array}$ \\
\hline Indoor sources & $\begin{array}{l}\text { Tobacco smoke, construction } \\
\text { materials, pressed-wood prod- } \\
\text { ucts, carpeting, paints, var- } \\
\text { nishes, floor finishes, sanitary } \\
\text { paper products }\end{array}$ & $\begin{array}{l}\text { Tobacco smoke, concrete and } \\
\text { plasterboard, dyes, household } \\
\text { fumigant, some air fresheners, } \\
\text { cooking, moth repellents }\end{array}$ & $\begin{array}{l}\text { Tobacco smoke, dyes, deter- } \\
\text { gents, glues, paints, furniture } \\
\text { wax; from derivatives: plastics, } \\
\text { resins, adhesives, nylon, lubri- } \\
\text { cants }\end{array}$ \\
\hline Outdoor sources & $\begin{array}{l}\text { Automobile exhaust, wild fires, } \\
\text { components for the transmis- } \\
\text { sion, electrical system, engine } \\
\text { block, door panels, axles, and } \\
\text { brake shoes }\end{array}$ & $\begin{array}{l}\text { Coal tar, rubbers, tanning } \\
\text { agents in leather industry, } \\
\text { dispersant for pesticides, } \\
\text { pyrotechnic special effects }\end{array}$ & $\begin{array}{l}\text { Automobile service stations, } \\
\text { gasoline additive, exhaust from } \\
\text { motor vehicles, pesticides, ex- } \\
\text { plosives, rubbers, wood smoke, } \\
\text { volcanic eruptions }\end{array}$ \\
\hline $\begin{array}{l}\text { Recommended exposure } \\
\text { limit (WHO, 2010) }\end{array}$ & $81 \mathrm{ppb}$ (30 min exposure) & $1.9 \mathrm{ppb}$ (annual average) & No safe level of exposure \\
\hline
\end{tabular}

* Data from the United States Environmental Protection Agency (EPA).

the drain current (the saturation current in Fig. 3 is the drain current at a drain-to-source voltage of $5 \mathrm{~V}$ ) has been measured, even if it is not possible to define a net tendency of the behavior of the SiC-FETs due to exposure to VOCs. The current's variation could be related to built-in defects present in the device or to the gate oxide on the interface. In terms of operating time under exposure to VOCs, SiC-FETs 1 and 2 were operated for $20 \mathrm{~h}$, SiC-FET 3 for $21 \mathrm{~h}$, SiC-FET 4 for $66 \mathrm{~h}, \mathrm{SiC}-\mathrm{FET} 5$ for $131 \mathrm{~h}$, and SiC-FET 6 for $218 \mathrm{~h}$.

\subsection{Gas tests}

Iridium-gate SiC-FET sensor devices were operated at a constant temperature between 300 and $330^{\circ} \mathrm{C}$, in dry air and under different levels of relative humidity $(\mathrm{RH})$ from 10 to $60 \%$. The response characteristics of all Ir-gate FET sensors to various concentrations of formaldehyde, naphthalene, and benzene at different temperatures and humidity levels were obtained operating the devices at a constant drain current and gate bias, adjusted in the ranges 15 to $25 \mu \mathrm{A}$ and 2.0 to $2.8 \mathrm{~V}$, respectively, so as to keep the drain-to-source voltage close to the saturation voltage, $V_{\mathrm{DS}}$, sat (at the onset of saturation), corresponding to an initial $V_{\mathrm{DS}}$ of around $0.8-0.9 \mathrm{~V}$. The voltage

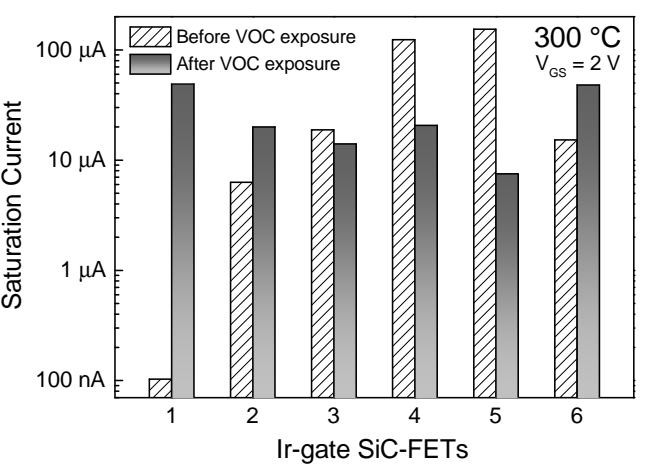

Figure 3. Saturation currents measured on six Ir-gate SiC-FETs at $300^{\circ} \mathrm{C}$ and $2 \mathrm{~V}$ applied gate bias, $V_{\mathrm{GS}}$, before and after exposure to VOCs.

drop between drain and source, $V_{\mathrm{DS}}$, was the sensor signal. Different concentrations of formaldehyde $\left(\mathrm{CH}_{2} \mathrm{O}\right)$, naphthalene $\left(\mathrm{C}_{10} \mathrm{H}_{8}\right)$, and benzene $\left(\mathrm{C}_{6} \mathrm{H}_{6}\right)$ were used to study the sensor's performance and characteristics. Sensor response, detection limit, sensitivity, response and recovery times, and repeatability of the sensor response were studied in dry air as well as in a humid atmosphere. 
Table 2. Gas specifications.

\begin{tabular}{lrrl}
\hline VOC & $\begin{array}{r}\text { Min. } \\
\text { concentration }\end{array}$ & $\begin{array}{r}\text { Max. } \\
\text { concentration }\end{array}$ & Gas source \\
\hline $\begin{array}{l}\text { Formaldehyde } \\
\text { Benzene }\end{array}$ & $0.1 \mathrm{ppb}$ & $1 \mathrm{ppm}$ & $\begin{array}{l}\text { Gas bottle } \\
7 \mathrm{ppb}\end{array}$ \\
$\begin{array}{l}\text { Permeation } \\
\text { oven at } 30^{\circ} \mathrm{C}\end{array}$ \\
Naphthalene & $0.1 \mathrm{ppb}$ & $25 \mathrm{ppb}$ & $\begin{array}{l}\text { Permeation } \\
\text { oven at } 60.7^{\circ} \mathrm{C} \\
\text { Permeation } \\
\text { oven at } 70^{\circ} \mathrm{C}\end{array}$ \\
\hline
\end{tabular}

The VOC gases were supplied by using an advanced gas mixing system consisting of two permeation ovens for supplying ultra-low concentrations of benzene and naphthalene, and a gas dilution section containing a gas bottle of formaldehyde (Helwig et al., 2014). Synthetic air, humidified by a water bubbler temperature stabilized at $20^{\circ} \mathrm{C}$, was used as a carrier gas in the permeation ovens as well as in the gas dilution section. The main advantage of using the same carrier gas in the whole system is to keep constant the contamination levels contained in the carrier gas and to establish a constant background not affecting the sensor response (Bur et al., 2014).

The gas mixing system is controlled by a LabVIEW program to keep the total flow over the sensor at a constant flow rate of $200 \mathrm{~mL} \mathrm{~min}^{-1}$. The temperature of the ovens was adjusted to reach the lowest VOC concentrations, and kept constant during measurements. Naphthalene was supplied from $50 \mathrm{ppb}$ down to $0.5 \mathrm{ppb}$, formaldehyde from $1 \mathrm{ppm}$ down to $0.1 \mathrm{ppb}$, and benzene from $7 \mathrm{ppb}$ down to $0.1 \mathrm{ppb}$. The gas specifications are summarized in Table 2.

\section{Results}

Figure 4 shows the sensor response to naphthalene at $300^{\circ} \mathrm{C}$ in dry air and under $20 \% \mathrm{RH}$. The sensor signals shown in the figure are smoothed using an adjacent-average filter to reduce the electronic noise ( $100 \mathrm{pts}$ smooth is equivalent to a sampling time of $100 \mathrm{~ms}$ ). During the same gas test, the sensor was exposed twice to the same concentrations of $\mathrm{C}_{10} \mathrm{H}_{8}$, but for two different durations, of $1 \mathrm{~h}$, and $15 \mathrm{~min}$. The results showed good repeatability within an error ranging from $1.6 \%$ at $50 \mathrm{ppb}$ to $7 \%$ at $2 \mathrm{ppb}$ in dry air, and from 8 to $11 \%$ at the same concentrations under $20 \% \mathrm{RH}$. The dependence of sensor response on VOC concentration in dry air and at $20 \% \mathrm{RH}$ is given in Fig. 5. The corresponding sensitivity, defined as the change in response magnitude for a certain change in gas concentration, is $7.5 \mathrm{mV} \mathrm{ppb}^{-1}$ in dry air, and $4.5 \mathrm{mV} \mathrm{ppb}^{-1}$ under $20 \% \mathrm{RH}$ at $2 \mathrm{ppb}$. The effect of humidity is significantly less evident at lower concentrations, decreasing the sensor response by a factor of 5.1 at $50 \mathrm{ppb}$, but only by a factor of 1.6 at $2 \mathrm{ppb}$. These results are in agreement with those previously obtained (Puglisi et al., 2014). The relative

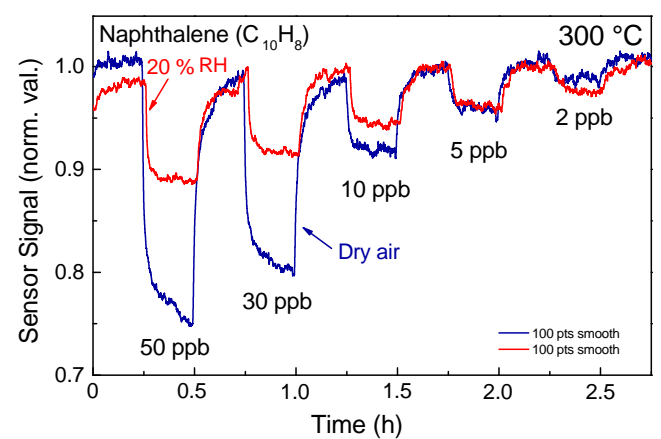

Figure 4. Sensor response to different concentrations of naphthalene $\left(\mathrm{C}_{10} \mathrm{H}_{8}\right)$ from 50 to $2 \mathrm{ppb}$ at $300{ }^{\circ} \mathrm{C}$ in dry air and under $20 \%$ relative humidity $(\mathrm{RH})$. The sensor signals are filtered to reduce the electronic noise. The value 100 pts smooth is equivalent to a sampling time of $100 \mathrm{~ms}$.

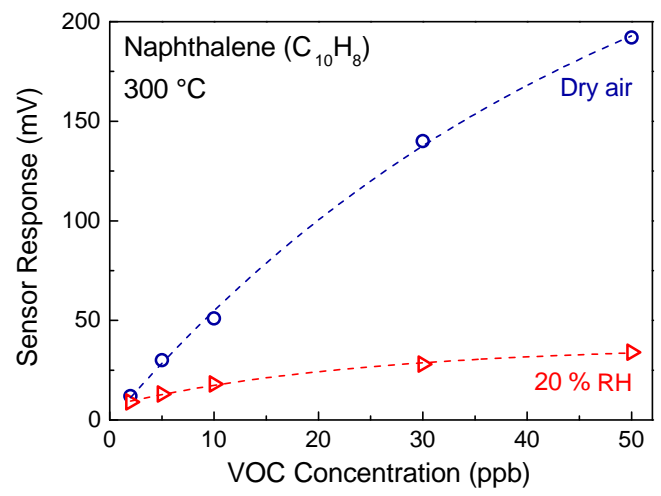

Figure 5. Effect of relative humidity on the sensor response to naphthalene $\left(\mathrm{C}_{10} \mathrm{H}_{8}\right)$ from 50 to $2 \mathrm{ppb}$ at $300^{\circ} \mathrm{C}$.

response, $S$, defined as

$S=\frac{V_{\mathrm{DS}(\mathrm{air})}-V_{\mathrm{DS}(\mathrm{VOC})}}{V_{\mathrm{DS}(\text { air })}} \times 100$,

where $V_{\mathrm{DS}(\text { air) }}$ and $V_{\mathrm{DS}(\mathrm{VOC})}$ are the sensor responses in background gas (synthetic air) and under exposure to the test gas (VOC), respectively, $9.7 \%$ at $50 \mathrm{ppb}$, and $2.5 \%$ at $2 \mathrm{ppb}$ under $20 \%$ RH.

From these results, the detection limit is expected to be less than $2 \mathrm{ppb}$. By varying the temperature of the permeation oven from 70 to $60.7^{\circ} \mathrm{C}$, it was possible to supply lower concentrations down to $0.5 \mathrm{ppb}$. Measurements were carried out at $330{ }^{\circ} \mathrm{C}$ from 20 to $60 \% \mathrm{RH}$, revealing a detection limit below $0.5 \mathrm{ppb}$ at any humidity level.

Figure 6 shows the sensor response to naphthalene at $330^{\circ} \mathrm{C}$, and $20 \% \mathrm{RH}$. The sensor signal has very low electronic noise (the sensor signal in the figure is not filtered) and shows a superb sensitivity to naphthalene in the sub-ppb range. The sensor response is $32 \mathrm{mV}$ at $0.5 \mathrm{ppb}$, corresponding to a relative response of $3.4 \%$. At high humidity levels, the relative response at $0.5 \mathrm{ppb}$ is $2.7 \%$ under $40 \% \mathrm{RH}$ (re- 


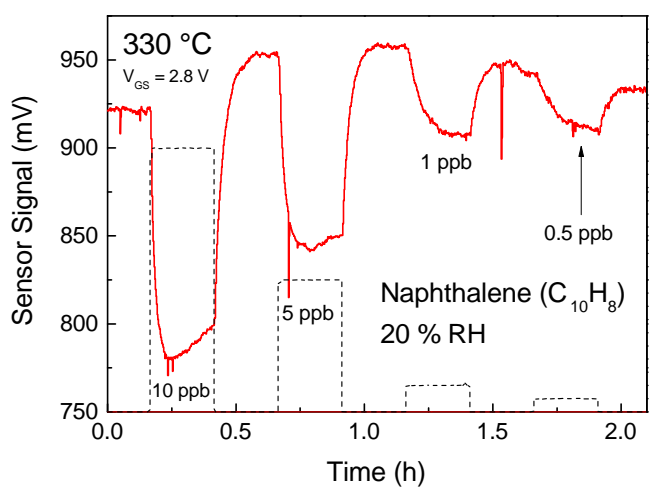

Figure 6. Sensor response to different concentrations of naphthalene $\left(\mathrm{C}_{10} \mathrm{H}_{8}\right)$ from 10 to $0.5 \mathrm{ppb}$ at $330^{\circ} \mathrm{C}$, and $20 \%$ relative humidity (RH). The sensor signal (not filtered in the figure) has very low electronic noise and shows superb sensitivity to naphthalene in the sub-ppb range.

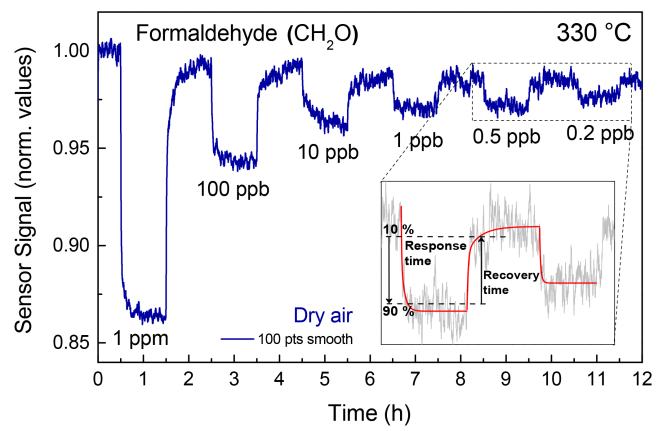

Figure 7. Sensor response to different concentrations of formaldehyde $\left(\mathrm{CH}_{2} \mathrm{O}\right)$ from $1 \mathrm{ppm}$ to $0.2 \mathrm{ppb}$ at $330^{\circ} \mathrm{C}$ in dry air. The sensor signal is filtered to reduce the electronic noise. The value $100 \mathrm{pts}$ smooth is equivalent to a sampling time of $100 \mathrm{~ms}$.

sponse time about $5 \mathrm{~min}$, recovery time about $10 \mathrm{~min}$ ), and $1.5 \%$ under $60 \% \mathrm{RH}$ (response time about $3 \mathrm{~min}$, recovery time about $6 \mathrm{~min}$ ). Such good results were possible also due to a significant reduction of the background electronic noise (0.6 mV standard deviation).

Figure 7 shows the sensor response to formaldehyde at $330{ }^{\circ} \mathrm{C}$ in dry air. The relative response ranges from $13.8 \%$ at $1 \mathrm{ppm}$ to $1.2 \%$ at the lowest tested concentration of $0.2 \mathrm{ppb}$. The sensor is extremely sensitive to $\mathrm{CH}_{2} \mathrm{O}$, showing a superb detection limit below $0.2 \mathrm{ppb}$ in dry air, but the effect of $\mathrm{RH}$ seems to be critical below $10 \mathrm{ppb}$ already under $10 \% \mathrm{RH}$, probably due to the hydrophilic nature of the molecule. Under the effect of $10 \% \mathrm{RH}$, the relative response ranges from $6.9 \%$ at $1 \mathrm{ppm}$ to $0.9 \%$ at $10 \mathrm{ppb}$. The dependence of sensor response on VOC concentration in dry air and at $10 \% \mathrm{RH}$ is given in Fig. 8. The effect of humidity is more evident at lower concentrations, decreasing the sensor response by a factor of 2.5 at $1 \mathrm{ppm}$, and by a factor of 4.2 at $10 \mathrm{ppb}$. This is opposite to the influence of humidity on the response to naphthalene.

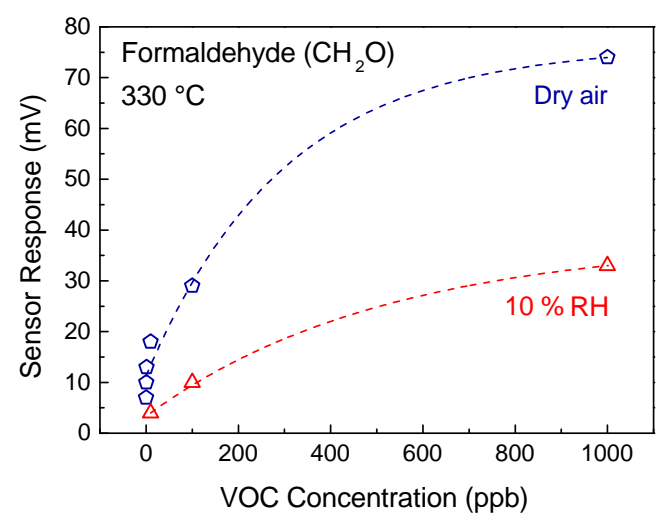

Figure 8. Effect of relative humidity on the sensor response to formaldehyde $\left(\mathrm{CH}_{2} \mathrm{O}\right)$ from $1 \mathrm{ppm}$ to $0.2 \mathrm{ppb}$ at $330^{\circ} \mathrm{C}$.

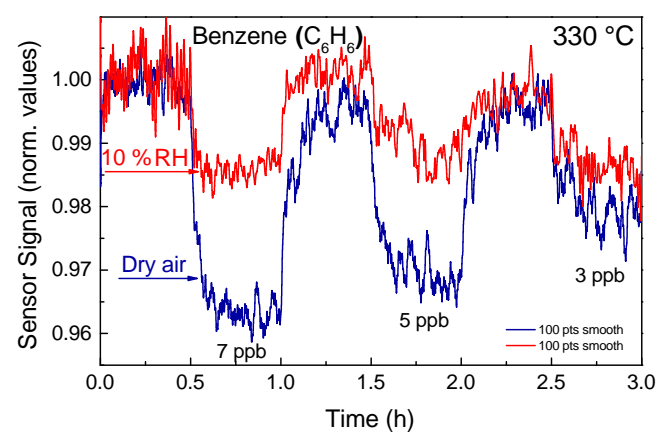

Figure 9. Sensor response to low concentrations of benzene $\left(\mathrm{C}_{6} \mathrm{H}_{6}\right)$ from 7 to $3 \mathrm{ppb}$ at $330{ }^{\circ} \mathrm{C}$ in dry air and under $10 \%$ relative humidity $(\mathrm{RH})$. The sensor signal is filtered to reduce the electronic noise. The value $100 \mathrm{pts}$ smooth is equivalent to a sampling time of $100 \mathrm{~ms}$.

Also in the case of formaldehyde, measurements were carried out at high humidity levels in order to investigate, in particular, the detection limit of the sensor device. The Ir-gate SiC-FET revealed a detection limit of $1 \mathrm{ppb}$ under $20 \% \mathrm{RH}$, $5 \mathrm{ppb}$ under $40 \% \mathrm{RH}$, and $10 \mathrm{ppb}$ under $60 \% \mathrm{RH}$. The relative response is $1.2 \%$ at $5 \mathrm{ppb}$ and $40 \% \mathrm{RH}$ (response time about $18 \mathrm{~min}$, recovery time about $16 \mathrm{~min}$ ), and $0.6 \%$ at $10 \mathrm{ppb}$ and $60 \%$ RH (response time about $1.5 \mathrm{~min}$, recovery time about $4 \mathrm{~min})$.

In the case of benzene, a significant improvement of the sensor sensitivity was reached compared to previous results (Puglisi et al., 2014), reducing the detection limit to the very low value of $0.2 \mathrm{ppb}$ under $20 \% \mathrm{RH}$.

During a first gas test carried out in dry air and under $10 \% \mathrm{RH}$, the relative response is $3.9 \%$ at $7 \mathrm{ppb}$ (sensitivity $3.1 \mathrm{mV} \mathrm{ppb}^{-1}$ ), and $1.8 \%$ at $3 \mathrm{ppb}$ (sensitivity $3.3 \mathrm{mV} \mathrm{ppb}^{-1}$ ) in dry air. Under the effect of $10 \% \mathrm{RH}$, the relative response is $1.5 \%$ at $7 \mathrm{ppb}$ (sensitivity $1 \mathrm{mV} \mathrm{ppb}^{-1}$ ), and $1.1 \%$ at $3 \mathrm{ppb}$ (sensitivity $1.7 \mathrm{mV} \mathrm{ppb}^{-1}$ ). The effect of humidity decreases the sensor response by a factor of 3.1 at $7 \mathrm{ppb}$, and by a factor of 2 at $3 \mathrm{ppb}$ (Fig. 9). 


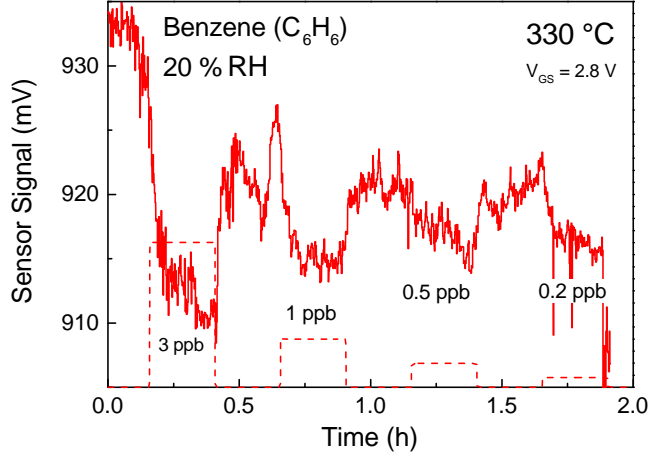

Figure 10. Sensor response to very low concentrations of benzene $\left(\mathrm{C}_{6} \mathrm{H}_{6}\right)$ from 3 to $0.2 \mathrm{ppb}$ at $330^{\circ} \mathrm{C}$ and $20 \% \mathrm{RH}$. The sensor signal is not filtered.

The test was repeated under $20 \% \mathrm{RH}$ at lower concentrations down to $0.1 \mathrm{ppb}$ (Fig. 10), showing a relative response of $1.6 \%$ at $3 \mathrm{ppb}$ (sensitivity $5 \mathrm{mV} \mathrm{ppb}^{-1}$ ), and of $0.5 \%$ at $0.2 \mathrm{ppb}$ (sensitivity $25 \mathrm{mV} \mathrm{ppb}^{-1}$ ).

At high humidity levels, a detection limit of $1-3$ ppb was measured up to $60 \% \mathrm{RH}$ with a relative response of $1 \%$ at $3 \mathrm{ppb}$ (sensitivity $2.3 \mathrm{mV} \mathrm{ppb}^{-1}$ ), and $0.7 \%$ at $1 \mathrm{ppb}$ (sensitivity $4 \mathrm{mV} \mathrm{ppb}^{-1}$ ) within a response/recovery time of a few minutes.

The detection limits of the studied VOCs as a function of relative humidity are shown in Fig. 11. In the case of naphthalene, it is only possible to say that the detection limit is below $0.5 \mathrm{ppb}$, since our gas mixing system does not supply $\mathrm{C}_{10} \mathrm{H}_{8}$ concentrations below $0.5 \mathrm{ppb}$.

The Ir-gate SiC-FETs were studied also by means of nanoscale structural and electrical characterization of the surface morphology and surface potential of the gate before and after exposure to VOCs (Fig. 12). The analysis has not revealed any significant degradation of the gate due to gas exposure. This means that the sensing layer is not degraded upon long-term exposure to elevated temperatures $\left(330^{\circ} \mathrm{C}\right)$ and repeated VOC adsorption/desorption. This is worth pointing out, as the target application (air quality control) will require long-term stability of the devices under such conditions. Other metals, commonly used as gate material, such as Pt, have been found to degrade (by delamination and restructuring by agglomeration, forming particles) upon long-term operation at similar or lower temperatures (Andersson et al., 2013).

\section{Discussion and conclusions}

In this work, we tested gas-sensitive Ir-gate SiC-FETs at constant temperature, in dry air and under different levels of relative humidity $(\mathrm{RH})$ from 10 to $60 \%$, demonstrating high performance of the sensor devices to be used for highly sensitive detection of specific volatile organic compounds (VOCs), in agreement with current legal requirements, es-

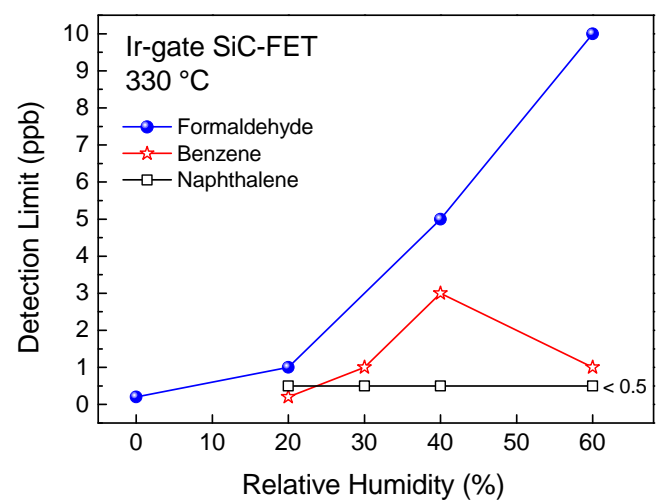

Figure 11. Detection limit for formaldehyde $\left(\mathrm{CH}_{2} \mathrm{O}\right)$, benzene $\left(\mathrm{C}_{6} \mathrm{H}_{6}\right)$, and naphthalene $\left(\mathrm{C}_{10} \mathrm{H}_{8}\right)$ as a function of relative humidity. In the case of $\mathrm{C}_{10} \mathrm{H}_{8}$, it is only possible to say that the detection limit is below $0.5 \mathrm{ppb}$, since our gas mixing system does not supply $\mathrm{C}_{10} \mathrm{H}_{8}$ concentrations below $0.5 \mathrm{ppb}$.
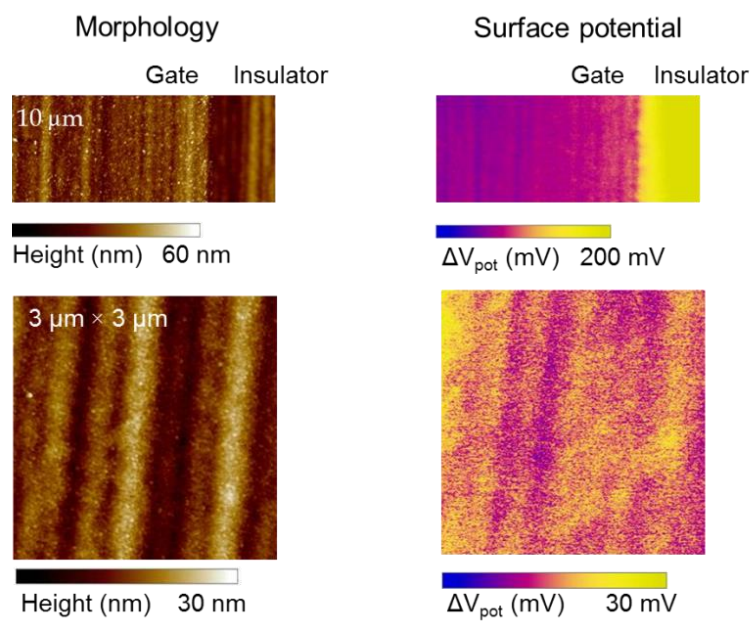

Figure 12. Surface morphology and surface potential of the Ir gate before (top figures) and after (bottom figures) 2 week exposure to VOCs at high temperature. It is worth pointing out that the sensing layer is not degraded upon long-term exposure to elevated temperatures and repeated VOC adsorption/desorption, which is extremely important for our target application (air quality control).

pecially in terms of detection limits. Good stability and repeatability of sensor response during 2 week operation was confirmed. Excellent detection limits of $1 \mathrm{ppb}$ for formaldehyde, $0.2 \mathrm{ppb}$ for benzene, and below $0.5 \mathrm{ppb}$ for naphthalene were measured under $20 \% \mathrm{RH}$ with a relative response of $0.4 \%$ for formaldehyde and benzene, and $3.4 \%$ for naphthalene. At high humidity levels, the sensors' performance and characteristics remained good, showing a detection limit of $10 \mathrm{ppb}$ for formaldehyde, about $1 \mathrm{ppb}$ for benzene, and below $0.5 \mathrm{ppb}$ for naphthalene with a relative response of $0.6 \%$ for formaldehyde, $0.7 \%$ for benzene, and $1.5 \%$ for naphthalene at $60 \% \mathrm{RH}$. These results are very encouraging for 
indoor air quality control, being below the threshold limits recommended by WHO guidelines.

Further investigation will include the use of temperature and bias cycling and smart data evaluation to study the selectivity of the sensors and achieve a quantitative discrimination of mixtures of the three studied compounds. VOC detection will be done in a more complex environment, changing the background by using typical interfering gases, such as ethanol. Other catalytic metals or metal oxides will be used as gate material and tested for comparison.

Moreover, interpretations of gas interaction on $\mathrm{Ir} / \mathrm{SiC}$ will be important for future studies on developing field effect based sensors for VOC detection.

Acknowledgements. The authors would like to thank P. Möller for his technical support, M. Bastuck for his contribution to the characterization of the sensors, SenSiC AB, Sweden, for supplying the sensors, and 3S-Sensors, Signal Processing, System GmbH, Germany, for supplying the hardware for sensor operation and read-out. This project has received funding from the European Union's Seventh Programme for research, technological development and demonstration, under grant agreement no. 604311 (SENSIndoor). The authors wish to dedicate this work to the memory of M. Cravino Vasta.

Edited by: M. Penza

Reviewed by: two anonymous referees

\section{References}

Agency for Toxic Substances and Disease Registry: United States Department of Health and Human Services, Public Health Service, Toxicological Profile for Naphthalene, 1methylnaphthalene, and 2-methylnaphthalene, updated September 2010.

Andersson, M., Petersson, H., Padban, N., Larfeldt, J., Holmberg, M., and Lloyd Spetz, A.: The characteristics and utility of SiCFE gas sensors for control of combustion in domestic heating systems, Proc. 3th IEEE Int. Conf. on Sensors, Vienna, Austria, 24-27 October, 1157-1160, 2004.

Andersson, M., Pearce, R., and Lloyd Spetz, A.: New generation SiC based Field Effect Transistor Gas Sensors, Sensor. Actuat. B-Chem., 167, 95-106, 2013.

Ashmore, M. R. and Dimitroulopoulou, C.: Personal exposure of children to air pollution, Atmos. Environ., 43, 128-141, 2009.

ATEB-EPA (Air Toxicology and Epidemiology Branch, Office of Environmental Health Hazard Assessment, California Environmental Protection Agency): Technical Support Document for the Derivation of Noncancer Reference Exposure Levels. Appendix D: Individual Acute, 8-Hour, and Chronic Reference Exposure Level Summaries, 145 pp., 388, 404, December 2008 (updated July 2014).

Bur, C., Reimann, P., Andersson, M., Lloyd Spetz, A., and Schütze, A.: Increasing the Selectivity of Pt-Gate SiC Field Effect Gas Sensors by Dynamic Temperature Modulation, IEEE Sens. J., 12, 1906-1913, 2012.
Bur, C., Andersson, M., Lloyd Spetz, A., and Schuetze, A.: Detecting Volatile Organic Compounds in the ppb Range with Gas Sensitive Platinum gate SiC-Field Effect Transistors, IEEE Sens. J., 14, 3221-3228, 2014.

EPA (United States Environmental Protection Agency): Indoor Air, Volatile Organic Compound (VOCs), Technical Overview, updated 9 November 2012.

Eriksson, M., Salomonsson, A., Lundström, I., Briand, D., and Åbom, A. E.: The influence of the insulator surface properties on the hydrogen response of field-effect gas sensors, J. Appl. Phys., 98, 34903-34908, 2005.

French Decree no. 2011-1727: Related to formaldehyde and benzene guide values for indoor air, December 2, 2011.

Gervais, J., Luukinen, B., Buhl, K., and Stone, D.: Naphthalene Technical Fact Sheet, National Pesticide Information Center, Oregon State University Extension Services, 2010.

Granham, C. I.: High-performance HVAC, Viridian Energy \& Environmental, LLC, available at: http://www.wbdg.org/resources/ hvac.php (last access: August 2014), 2009.

Helwig, N., Schüler, M., Bur, C., Schütze, A., and Sauerwald, T.: Gas mixing apparatus for automated gas sensor characterization, Measurement Science and Technology, 25, 9 pp., 055903, doi:10.1088/0957-0233/25/5/055903, 2014.

Lloyd Spetz, A., Nakagomi, S., and Savage, S.: High-Temperature SiC-FET Chemical Gas Sensors, in: Advances in Silicon Carbide Processing and Applications, edited by: Saddow, S. E. and Agarwal, A., Artech House, Inc., Chapter 2, 29-67, 2004.

Lloyd Spetz, A., Darmastuti, Z., Bur, C., Huotari, J., Bjorklund, R., Lindqvist, N., Lappalainen, J., Jantunen, H., Schuetze, A., and Andersson, M.: Improved chemical sensors track and control emissions, SPIE Newsroom, 1 May, 2013a.

Lloyd Spetz, A., Huotari, J., Bur, C., Bjorklund, R., Lappalainen, J., Jantunen, H., Schuetze, A., and Andersson, M.: Chemical sensor systems for emission control from combustion, Sensor. Actuat. B-Chem., 187, 184-190, 2013b.

Puglisi, D., Eriksson, J., Bur, C., Schütze, A., Lloyd Spetz, A., and Andersson, M.: Silicon carbide field effect transistors for detection of ultra-low concentrations of hazardous volatile organic compounds, Mat. Sci. Forum, 778-780, 1067-1070, 2014.

Rumchev, K. B., Spickett, J. T., Bulsara, M. K., Phillips, M. R., and Stick, S. M.: Domestic exposure to formaldehyde significantly increases the risk of asthma in young children, Eur. Respir. J., 20, 403-408, 2002.

Salonen, H., Pasanen, A.-L., Lappalainen, S., Riuttala, H., Tuomi, T., Pasanen, P., Bäck, B., and Reijula, K.: Volatile Organic Compounds and Formaldehyde as Explaining Factors for Sensory Irritation in Office Environments, J. Occup. Environ. Hyg., 6, 239247, 2009.

Schalwig, J., Müller, G., Karrer, U., Eickhoff, M., Ambacher, O., Stutzmann, M., Görgens, L., and Dollinger, G.: Hydrogen response mechanism of Pt-GaN Schottky diodes, Appl. Phys. Lett., 80, 1222-1224, 2002.

Wallace, L. A.: The Total Exposure Assessment Methodology (TEAM) Study: Summary and Analysis, Volume I, Office of Research and Development, U.S. Environmental Protection Agency, Washington, D.C., 1987.

WHO (World Health Organization): Regional Office for Europe, WHO Guidelines for Indoor Air Quality: Selected Pollutants, ISBN 978928900213 4, 2010. 